\title{
UMA BREVE REFLEXÃO SOBRE A ATUAL APROPRIAÇÃO NO BAIXIO DO VIADUTO TANNEL ABBUD EM PRESIDENTE PRUDENTE/SP.
}

\author{
Maria Gabriela Salvino Contre, Yeda Ruiz Maria, Victor Martins De Aguiar \\ Universidade do Oeste Paulista. Curso de Arquitetura e Urbanismo. Presidente Prudente - SP. E-mail: \\ contre.mgs@gmail.com
}

\section{RESUMO}

A produção de descontinuidades, tais como viadutos, rotatórias e canteiros centrais, tem se tornado algo comum desde o começo do século XX. Os aspectos reproduzidos pela inserção dessas estruturas tiveram influências ao planejamento contemporâneo. O presente artigo tem como estudo de caso o Viaduto Tannel Abbud, localizado na cidade de Presidente Prudente -SP, em busca de analisar como tem ocorrido a apropriação no baixio do mesmo, por parte da população. Para tanto faz-se necessário levantamentos bibliográfico, documental e observações in loco. Os resultados obtidos foram que, as atmosferas criadas vão de acordo com que o espaço oferece, dessa forma foi possível perceber que quando não há diretriz adequada unificando as diversidades, esses locais tornam-se ociosos e propícios para uso marginal.

Palavras chave: Descontinuidades Urbanas; Viadutos; Presidente Prudente - SP.

\section{A BRIEF REFLECTION ON THE CURRENT APPROPRIATION IN THE TANNEL ABBUD VIADUTE BASS IN PRESIDENTE PRUDENTE / SP.}

\begin{abstract}
The production of discontinuities, such as viaducts, roundabouts and centrals, has been a mistake since the early twentieth century. The controls reproduced by the control of structures have influenced the contemporary planning. The present article has as reference the case of the Tannel Abbud Viaduct, located in the city of Presidente Prudente - SP, in search of analysis as having occurred in the lowlands, by the population. For such, it makes bibliographical, documentary and on-site observations. The results were those, while the applied atmospheres were in accordance with the space offerings, as well as the possibilities of using the resources for marginal use.
\end{abstract}

Keywords: Urban Discontinuities; Viaducts; Presidente Prudente - SP.

\section{INTRODUÇÃO}

A produção de descontinuidades tais como viadutos, rotatórias e canteiros centrais, tem se tornado algo comum desde o começo do século XX; a busca incansável pela modernização deixa a cidade comparada a uma vitrine de gestões políticas; as estratégias de marketing urbano utilizadas pelas lideranças locais se tornaram de fundamental importância para a divulgação dos atributos dos diferentes lugares e das imagens construídas. São criados verdadeiros cenários, que na maioria das vezes, omitem a realidade, aumentando a capacidade de atratividade do produto cidade, transformando os cidadãos em meros figurantes, atores secundários de seu roteiro (SÁNCHEZ, 1999). Atualmente, as cidades brasileiras sofrem os efeitos dessa modernização com espaços inutilizáveis, que tem sido objeto de estudo de muitos urbanistas, tais como o viaduto e embaixo deles. 
Para entender os aspectos reproduzidos pela inserção de estruturas desse porte, que ultrapassa o percurso entre duas quadras para o transeunte, ou impede a transposição entre ele, é necessário, mesmo que de forma sucinta, contextualizar o elemento viaduto a fim de entender de que forma ele foi implantado e porque atualmente ele ainda é entendido como símbolo de progresso.

Como qualquer transformação, a cidade também possui suas modificações de acordo com avanços tecnológicos, esses que influenciam até hoje no modo de se fazer nossas cidades. É possível entender esse processo do qual o Brasil fez parte, tendo recorte temporal a partir do período de industrialização automobilística, buscando compreender suas influências ao planejamento contemporâneo.

A presente pesquisa tem como estudo de caso o Viaduto Tannel Abbud, localizado na cidade de Presidente Prudente, no extremo oeste do estado de São Paulo, o qual foi inserido no núcleo de formação inicial da cidade (FIGURA 1).

Figura 1. Localização do Viaduto Tannel Abbud na malha urbana de Presidente Prudente -SP.

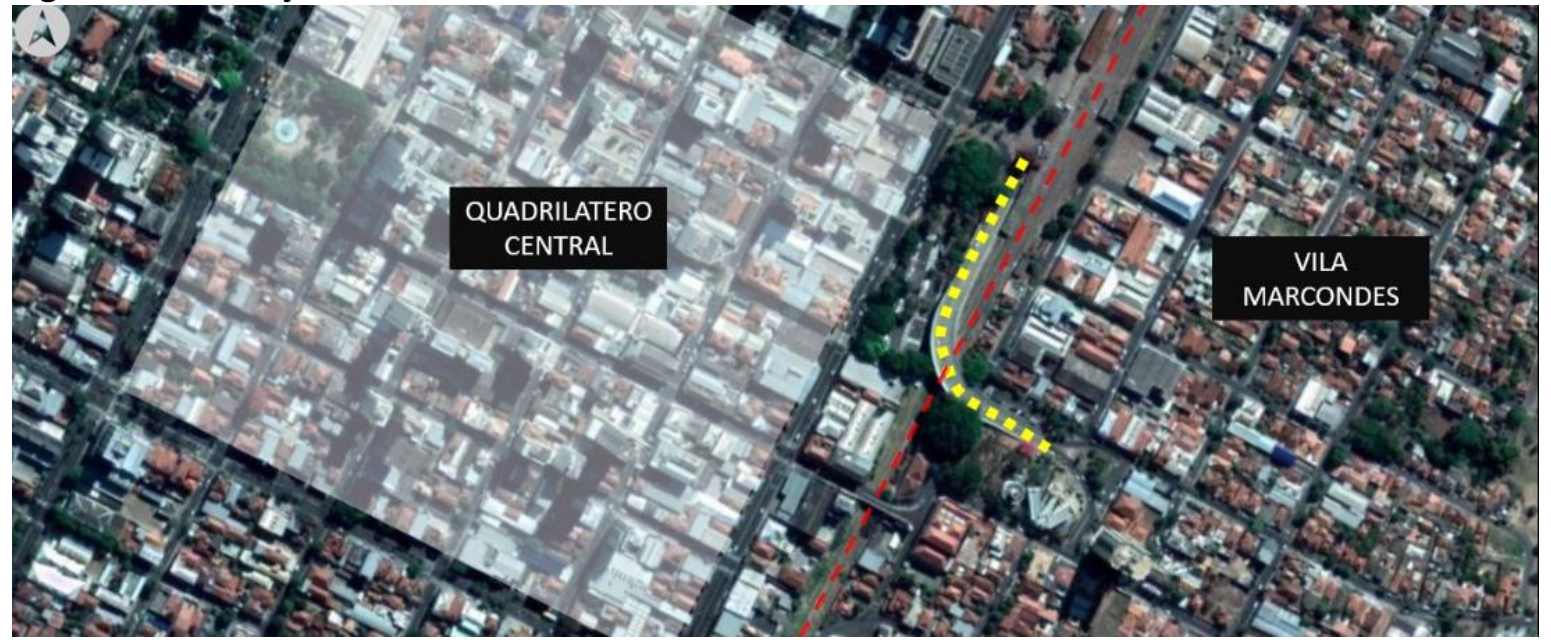

Fonte: Google Maps (2019). Editado pela autora, 2019.

Esse no qual, tem como caraterística a composição pelos os bairros Vila Marcondes e Quadrilátero Central, sendo que o viaduto (em amarelo) acentuou ainda mais a segregação socioespacial que já tinha sido estabelecido pela linha férrea (em vermelho).

Neste sentido, a presente pesquisa busca compreender as relações históricas e o modo de pensar o processo de projeção das cidades e seus resultados na contemporaneidade, tratando o modo como as apropriações têm se adaptado à um espaço físico que não atende dinâmicas distintas obtendo como objeto de estudo o Viaduto Tannel Abbud, localizado em Presidente Prudente - SP. Especificamente pretende-se analisar como tem ocorrido a apropriação por parte da população embaixo do Viaduto Tannel Abbud, localizado em Presidente Prudente - SP.

\section{METODOLOGIA.}

Para tanto faz-se necessário levantamentos bibliográficos e documental, esses que envolvem possíveis medidas da Prefeitura
Municipal para aquele espaço, buscando compreender a relevância de algumas alterações e a negligência de outras. Além de documentos disponibilizados no Web site oficial da Prefeitura da cidade de Presidente Prudente - SP e observações in loco afim de entender a dinâmica do espaço, ou existência de fatos que não constam na literatura.

A pesquisa bibliográfica e documental será o meio utilizado para identificar os fatos históricos e a relação bairros, viaduto e indivíduos. Esses documentos serão utilizados como fontes de informações, indicações e esclarecimentos que trazem seu conteúdo para elucidar determinadas questões e servir de prova para outras, de acordo com o interesse do pesquisador. Nesta perspectiva, entende-se que a memória coletiva poderá documentar fatos relevantes e concisos. 


\section{O SURGIMENTO DO VIADUTO E SEU CONTEXTO EM PRESIDENTE PRUDENTE - SP.}

A cidade contemporânea é palco de profundas mudanças sociais, culturais e tecnológicas e é um dos temas centrais da discussão interdisciplinar, redefinindo-se os seus domínios, limites e práticas, enquanto se assiste à (re)significação do seu conceito (COUTINHO, 2007).

Parte dessas mudanças sociais decorrem do automóvel, fator esse que fazia transitório a visão sobre a cidade e sua construção. No início do século XX, nos Estados Unidos e Europa, a indústria automobilística, que revolucionou os meios de produção, expandiu os padrões de consumo, influenciou o desenvolvimento do transporte rodoviário e estruturou seu poder perante economias centrais e periféricas (PEREIRA; LESSA, 2011).

No contexto brasileiro, segundo Pereira e Lessa (2011), na década de 1950 no Brasil, o governo de Juscelino Kubitschek assumiu a presidência da república com o discurso de modernizar e transformar a economia brasileira por meio de um ambicioso plano de governo, capaz de fazer o Brasil crescer "cinquenta anos em cinco", o chamado "Plano de Metas" (1956 1960), que previa os investimentos em setores estratégicos da economia brasileira, como

Figura 2. Presidente Prudente -SP em 1923.

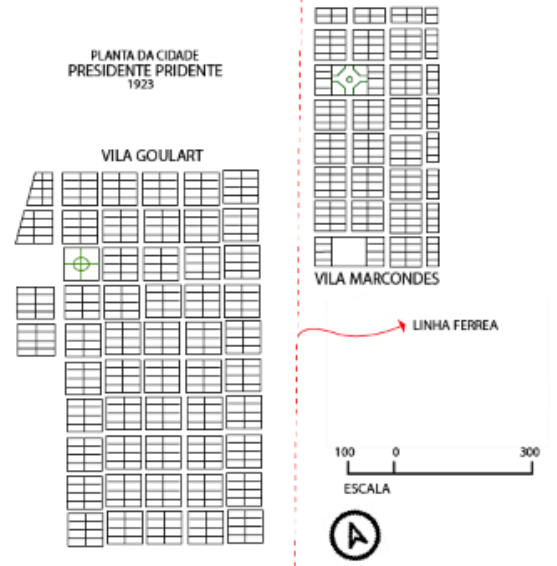

Fonte: Beltrão (1983). Editado pela autora, 2019.

Por outro lado, Coronel Manoel Goulart, esteve mais preocupado em promover a ocupação do território (atual quadrilátero central), permanecendo no local, facilitando a venda e aquisição dos lotes, inclusive realizando trocas com produção agrícola (HIRAO, 2008).

Atualmente tem-se uma dinâmica completamente diferente para cada bairro em energia, transporte, alimentação, indústria de base, educação e construção de Brasília. Nesse sentido, se deu a expansão da infraestrutura rodoviária que buscava atender às necessidades dos complexos industriais automobilísticos que se instalaram no Brasil.

Toda essa mudança na estrutura brasileira, trouxe resultados para a cidade. Como efeito desse urbanismo rodoviarista, implantaram-se ações desestruturadoras no tecido urbano: expansões desnecessárias da malha urbana, construção aleatória e muitas vezes inadequada do sistema viário, ocupando os fundos de vale e impermeabilizando várzeas (GROSTEIN, 2010).

Na realidade de Presidente Prudente - SP, uma cidade do extremo oeste Paulista com cerca de 223.749 habitantes essas estruturas chegaram por volta de 1970-1980. De acordo com Hirao (2008) a cidade obteve seu processo de formação a partir de dois núcleos urbanos que tiveram características distintas (FIGURA 2). Em 1919, o Coronel José Soares Marcondes, segundo Abreu (1972), dono de uma empresa colonizadora, chegava a região para dar início à venda de terras que compreendiam a região que ia de Montalvão até o limite da Fazenda Pirapó-Santo Anastácio. 
ainda, como cita Hirao (2008), entre esses bairros, a faixa abandonada da estrada de ferro, linear, vazia, e com ocupações consideradas marginais, divide esses lados e garante a permanência dessa diversidade de atmosferas da cidade (em cinza da FIGURA 3).

Figura 3: Mapa de uso e ocupação.

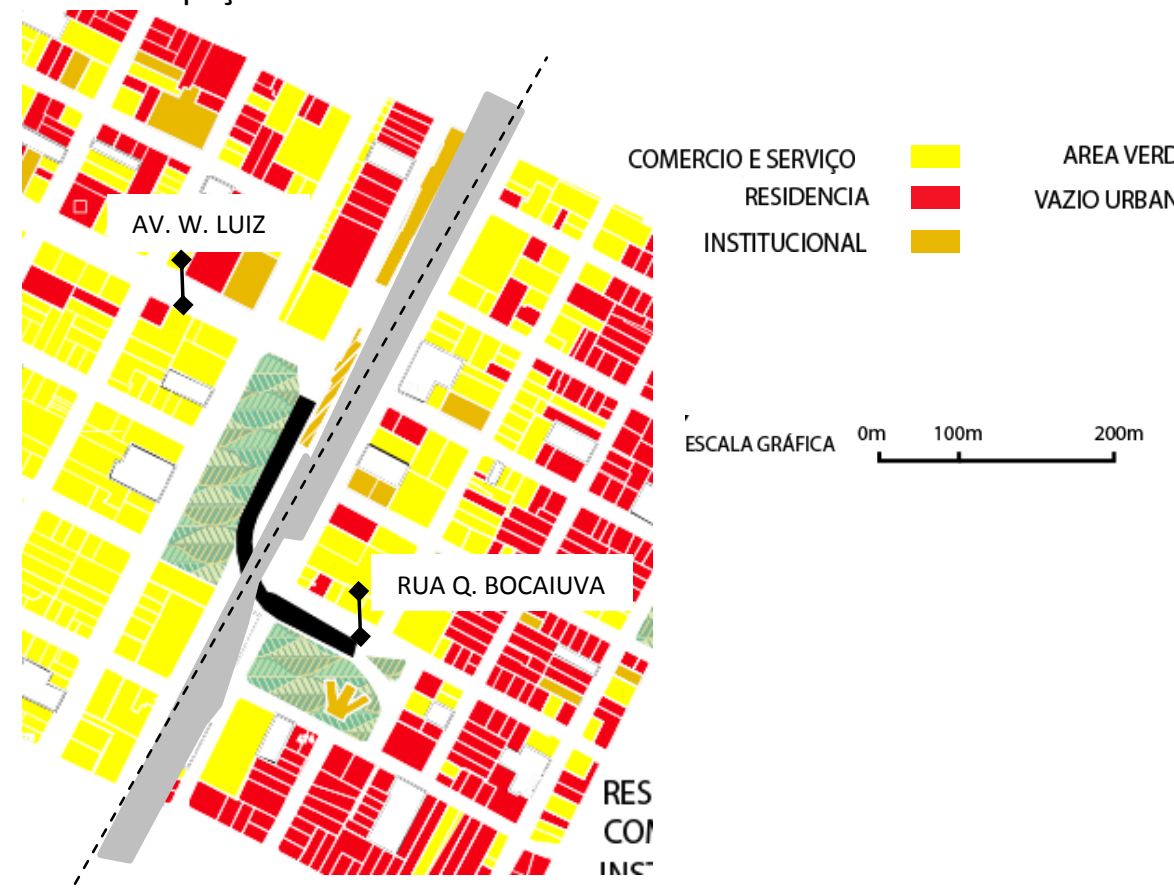

Fonte: Prefeitura de Presidente Prudente, editado pela autora, 2019.

$\mathrm{Na}$ faixa dos trilhos da ferrovia, no começo dos anos 1980, uma intervenção incisiva com a construção do Viaduto Tannel Abbud conectou as vilas pelas avenidas Washington Luiz e Quintino Bocaiuva, proporcionando fluidez de tráfego de veículos, coerente com os ideais progressistas da época (HIRAO, 2008). O autor ainda reforça que a inserção de uma estrutura desse porte interfere consideravelmente na paisagem urbana.

A inserção do viaduto passa longe de ser um complemento da cidade real, nas palavras de Debord (1967), ele é algo separado, que se torna o foco do olhar do iludido e da falsa consciência, a unificação que realiza não é outra coisa senão a linguagem oficial da separação generalizada.

\section{APROPRIAÇÕES NO VIADUTO TANNEL ABBUD}

Agostini et al. (2005) comenta que os viadutos urbanos e passarelas são componentes da infraestrutura urbana, atendendo prioritariamente e quase exclusivamente à circulação de veículos, servindo de transposição de fundos de vales, vias férreas, cruzamentos de vias etc. Um olhar mais atento sobre estes componentes revela que, além dessas funções, eles propiciam, através de suas características espaciais e construtivas, o surgimento de áreas intersticiais e marginais livres. Entretanto, como não são contempladas com o planejamento funcional, estas áreas são ocupadas informalmente e, em geral, de maneira precária. No caso da cidade de Presidente Prudente - SP o viaduto Tannel Abbud se consolidou com o espaço ocioso em seu baixio, e esse espaço está fragmentado em barreiras como demarcado na imagem de implantação do local em vermelho (FIGURA 4). 
Figura 4. Figura e fundo setorização e barreiras demarcadas do baixio do viaduto.

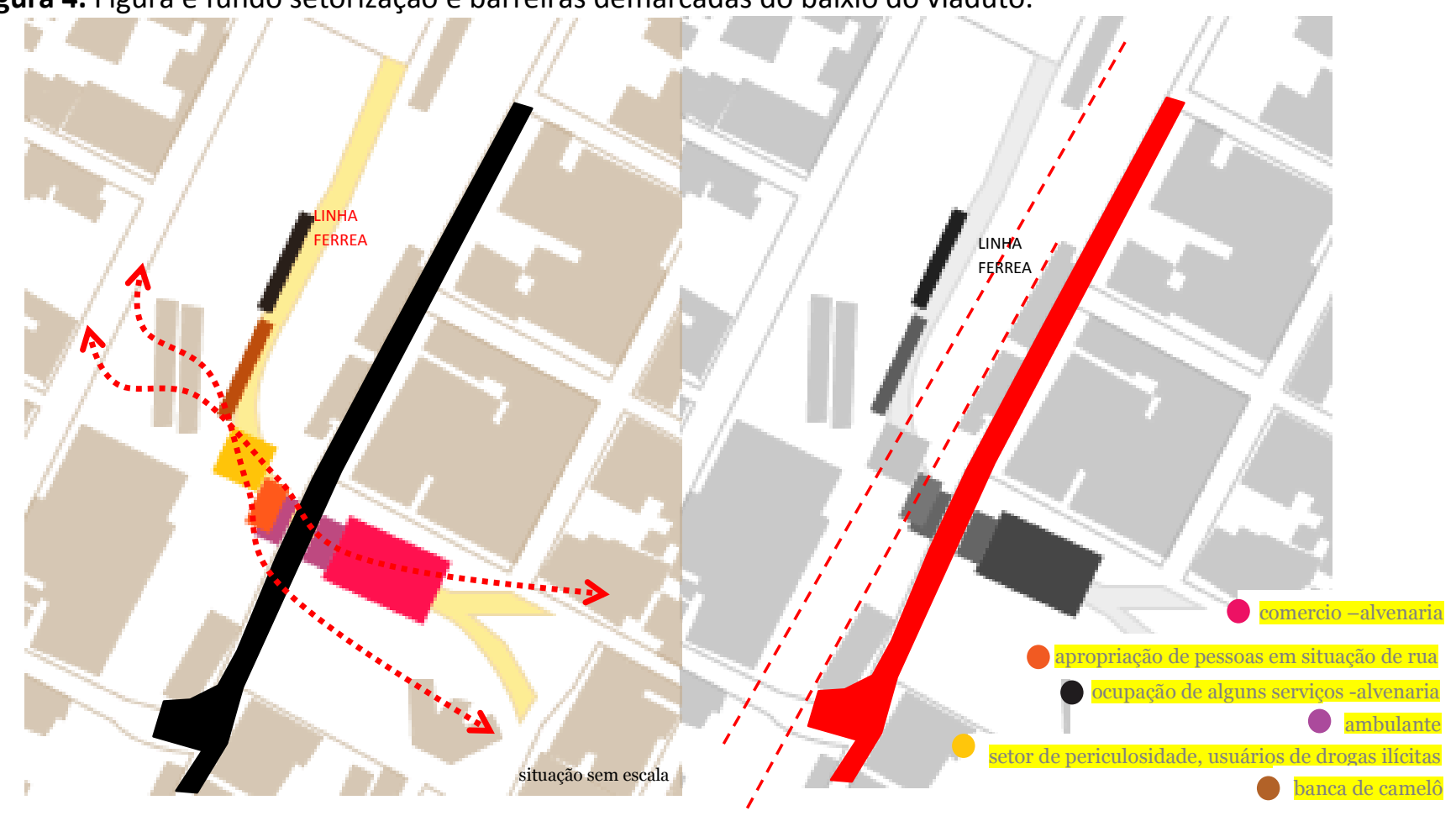

Fonte: Google Maps (2019). Editado pela autora 2019.

O eixo de sombra então, migra entre ambulantes e pessoas em situação de rua, que adotaram o local. Os ambulantes pelo rotineiro fluxo de pessoas migrando entre vila Marcondes e centro. Quanto as pessoas em situação de rua, o viaduto oferece uma cobertura protegida, possuindo barreiras, o que pode ser sinônimo de segurança para quem não quer ser visto dentro da malha urbana.

As atmosferas criadas foram definidas de acordo com o que o espaço ofereceu, muros, ocupações, comercializações, isso tudo se encaixa do modo como o viaduto conecta-se ou não conecta-se com a estrutura urbana, na perspectiva de um trecho da estrutura é possível notar os usos citados acima junto a cobertura (FIGURA 5). 
Figura 5. Vista da estrutura pela vila Marcondes.

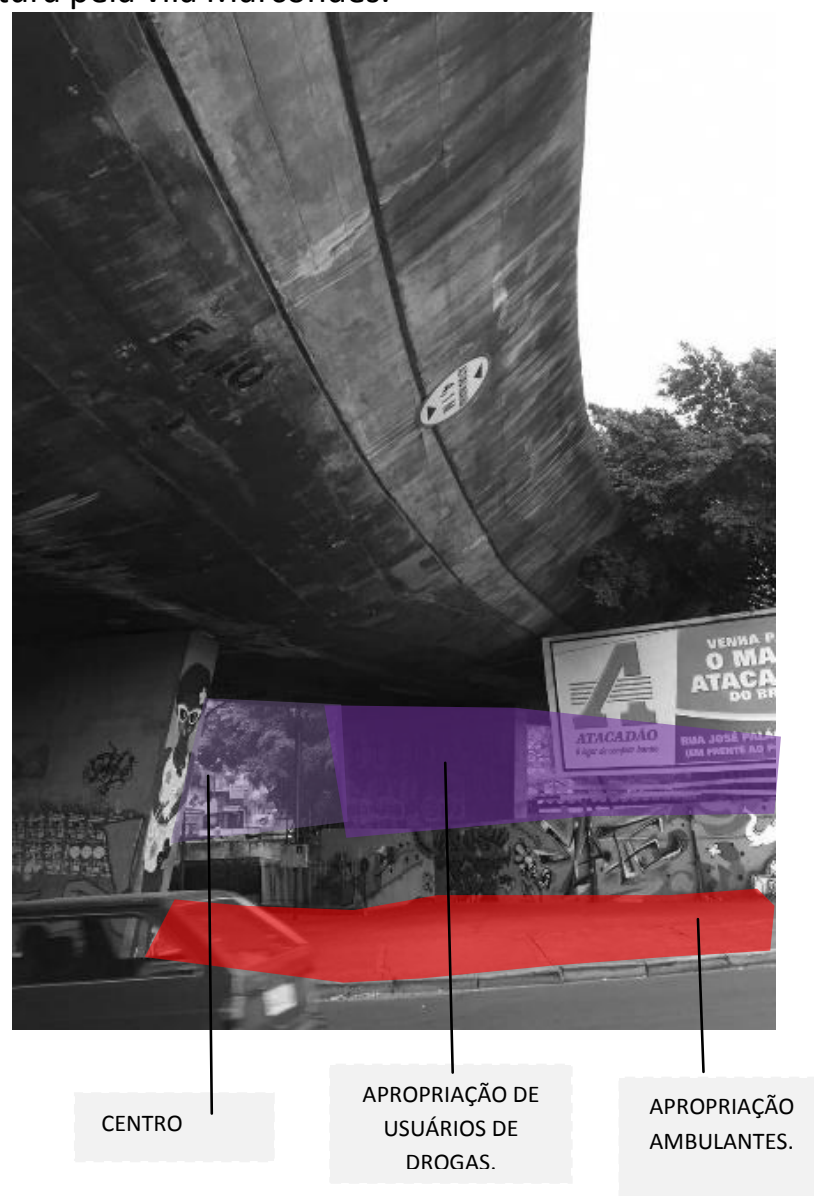

Fonte: Arquivo pessoal da autora (2019).

Apresentado os respectivos esquemas de setorização é possível através de mapas (FIGURA 6) é possível fazer algumas correlações do uso do espaço com a malha urbana. Tratando do camelódromo, ocupações consideradas marginais e as apropriações de ambulantes, dinâmicas destoantes, que não se conectam com a infraestrutura da cidade locadas em uma curta extensão (o baixio do viaduto) se comparado à escala do centro.

Figura 6. Implantação dos setores perante a malha urbana.

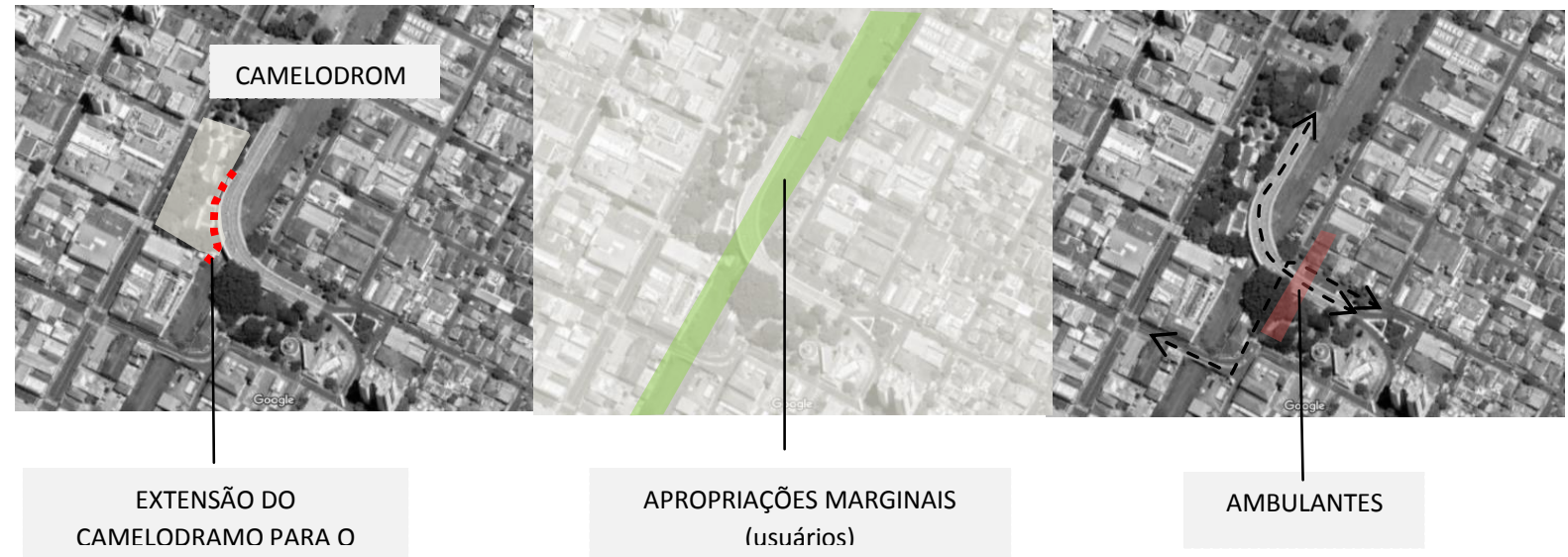

Fonte: Google Maps (2019). Editado pela autora, 2019. 
Ao localizar cada setor e suas respectivas implantações é possível entender sua atual apropriação, visto que, são lugares que se formaram informalmente, moldando-se a realidade da malha urbana.

No primeiro caso citado no setor de extensão do camelódromo trata-se de uma apropriação que aconteceu ao longo do tempo e que acentuou uma barreira visual já presente devido à construção do viaduto, ${ }^{1}$ veja (FIGURA 7).

\footnotetext{
1 Buscava-se a melhoria entre os acessos da área central e Vila Marcondes e a solução encontrada na época foi a implantação do Viaduto Tannel Abbud, no ano de 1970 para a travessia de carros sob os trilhos da linha férrea (BISPO, 2011).
} 
Figura 7. Vista do camelódromo.

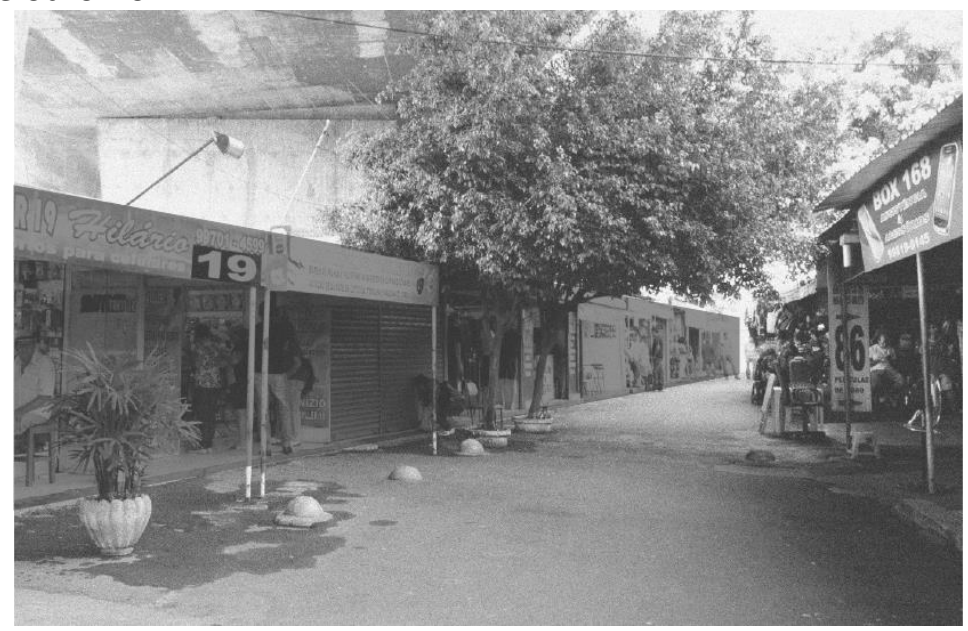

Fonte: Portal Prudentino (2019). Editado pela autora 2019.

Esse modo de ocupação foi decorrente à extensão dos limites impostos pelo governo municipal de Presidente Prudente, segundo Alvim (2019) nos anos 2000, na tentativa de revitalizar e regularizar o comércio informal da Praça da Bandeira, o poder público transformou parte de sua área em shopping popular aberto. Foram derrubadas árvores para colocação de boxes comerciais.

O local ficou conhecido como "camelódromo" e passou a atrair inúmeros consumidores ávidos pelas novidades do comércio popular, principalmente eletrônicos "importados". Com o passar do tempo, o número de camelos ilegais ultrapassou os boxes regulares, instalando uma situação de conflito.

Como citado, devido à essa tendência de a cidade virar as costas para a linha sem refletir em seus potenciais, no próximo trecho em discussão, que se constitui na malha ferroviária margeando os "fundos" dessa extensão do camelódromo (FIGURA 8).

Figura 8: Malha ferroviária, sombreamento do viaduto Tannel Abbud.

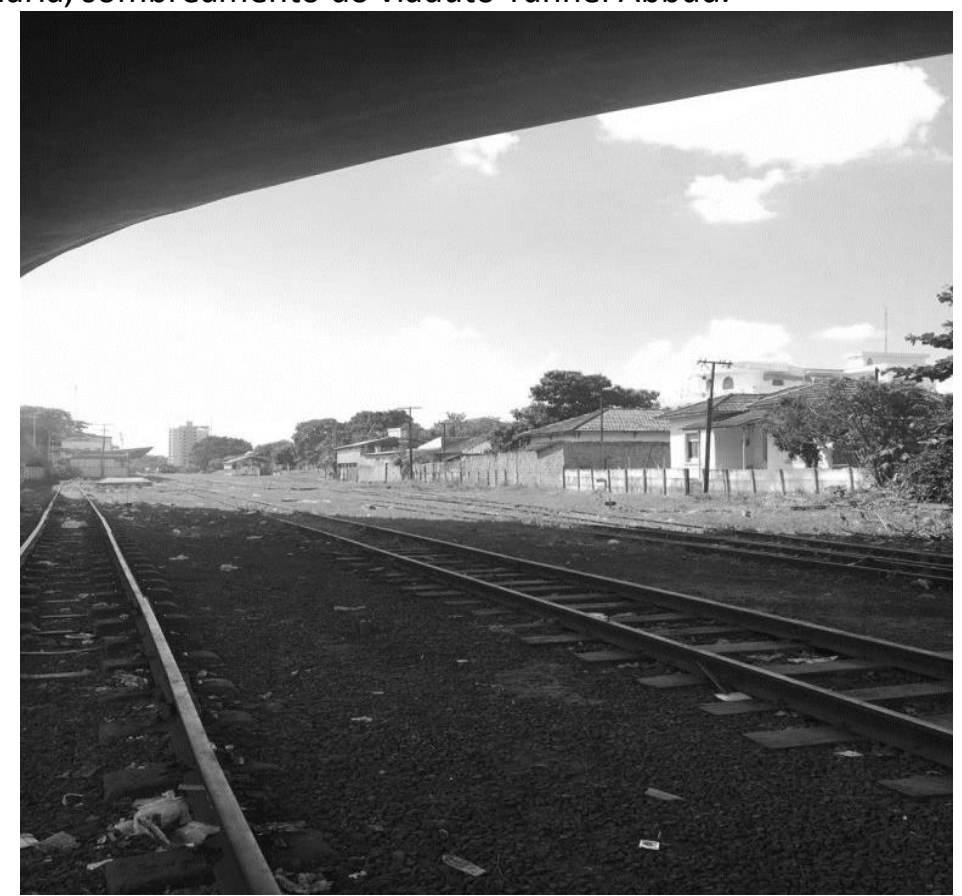

Fonte: Arquivo pessoal da autora (2019). 
Através dessa imagem, constata-se a questão de barreiras físicas na circulação, resultando em má conexão de setores presentes o que deixa um espaço segregado, e visto pela perspectiva de quem não quer ser observado, torna-se um espaço ideal para o uso de drogas. 0 que no geral, lugares geralmente se transformam com o tempo e esses usuários migram, como afirma Miziara (2004), os habitantes de rua moldam seus corpos à geografia urbana, mas quando esses lugares permanecem intactos no tempo-espaço o local fica estático e cria-se um estigma, como na área apresentada. Além disso, a estrutura do viaduto oferece um abrigo, que não expõe esses usuários às intemperes, sol e chuva.

É preciso entender que, apesar de estarem invisíveis, essas pessoas ainda sobrevivem com o que a cidade oferece, a cidade é a luta diária para o alimento, garantia de roupas e possíveis tratamentos, logo, a inserção do viaduto Tannel Abbud na área central sob um local já esquecido pela cidade, oferecendo uma sombra de quase 290 metros de extensão propõe uma gama de possibilidades, negativas e positivas.

No entanto, como a linha férrea é cercada por muros, ela fica entendida como algo isolado da malha dividindo duas atmosferas, uma central e outra residencial, a vila Marcondes. Por conta dessa má conexão na área da vila Marcondes, suas potencialidades de permanência e área de lazer dentro de uma área central, não são desenvolvidas e aproveitadas. Nesse caso, ao fazer a transposição entre os dois setores discutidos nota-se apenas a presença de ambulantes e algumas pessoas em situação de rua transitando (FIGURA 9).

Figura 9. Perspectiva da rua Floriano Peixoto.

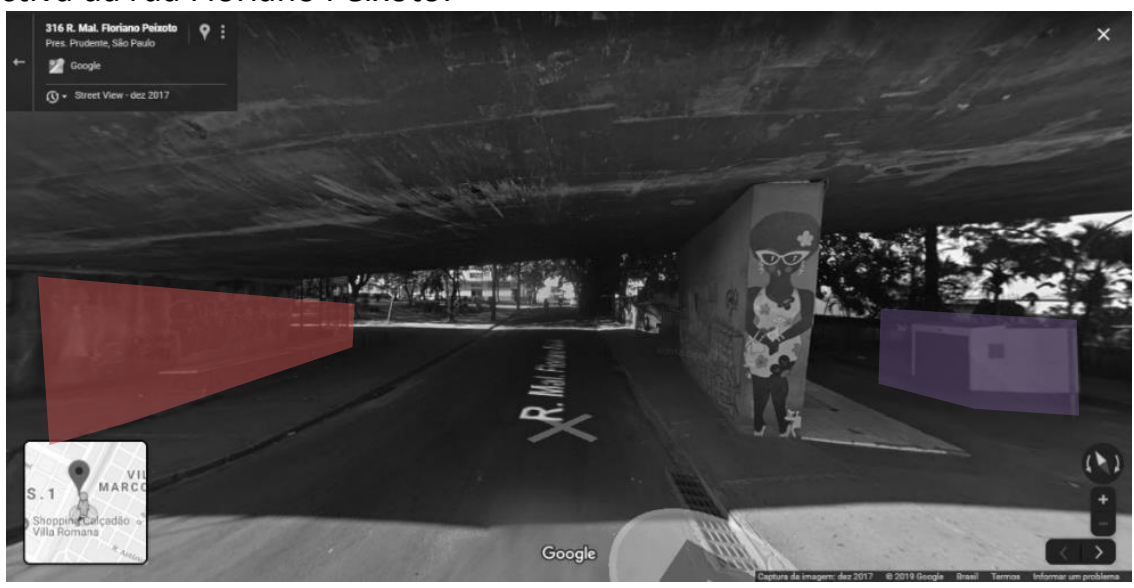

Fonte: Google Street View (2017). Editado pela autora, 2019.

Para Jane Jacobs (1961), a cidade é um grande cenário de vivências, das relações de poder, diferenças sociais, arquitetônicas, de paisagens e da falta de respeito com o principal personagem, o indivíduo enquanto cidadão. $\mathrm{E}$ dentro dessa perspectiva na área analisada diferenças de dinâmicas é um potencial à ser explorado, o olhar deve ser como o usuário se relaciona com essas diferentes dinâmicas.

Essa relação entre usuário com a cidade promovendo uma dinâmica não deve ser separado por limites físicos.

$$
\begin{aligned}
& \text { "Muito mais do que um } \\
& \text { espaço urbano fechado, } \\
& \text { recortado por ruas e }
\end{aligned}
$$

avenidas, construído com blocos de concreto e lajes de aço... a dominar todas as paisagens, a cidade é... um território de relações no qual cada cidadão/cidadã busca satisfazer suas necessidades e realizar seus quereres. (...) É uma realidade viva, pulsante. Ela é composta e compõe uma rede de fluxos de pessoas, mercadorias, matérias... energias em 
constante movimento" (GAVAZZA, 2013).

\section{MEDIDAS ATUAIS NO LOCAL}

$\mathrm{Na}$ tentativa de sanar um dos três problemas abordados, a Prefeitura de Presidente Prudente - SP, tem o objetivo de realocar 32 boxes que está margeando a linha, com base no decreto 16.462/2004, de autoria do ex-prefeito Agripino de Oliveira Lima Filho as instalações que excedessem 240 boxes estariam se apropriando do espaço de forma irregular. Esses 32 boxes que excederam o limite sugerido estão atualmente (ano 2019) em discussão para a possível remoção.

Essas decisões permanecem em contradições, visto que as medidas propostas pela Prefeitura Municipal para realocação estão implantadas no mesmo local, apenas com medidas reduzidas (não foi divulgado proporções exatas) (FIGURA 10).

Figura 9. Perspectiva da rua Floriano Peixoto.

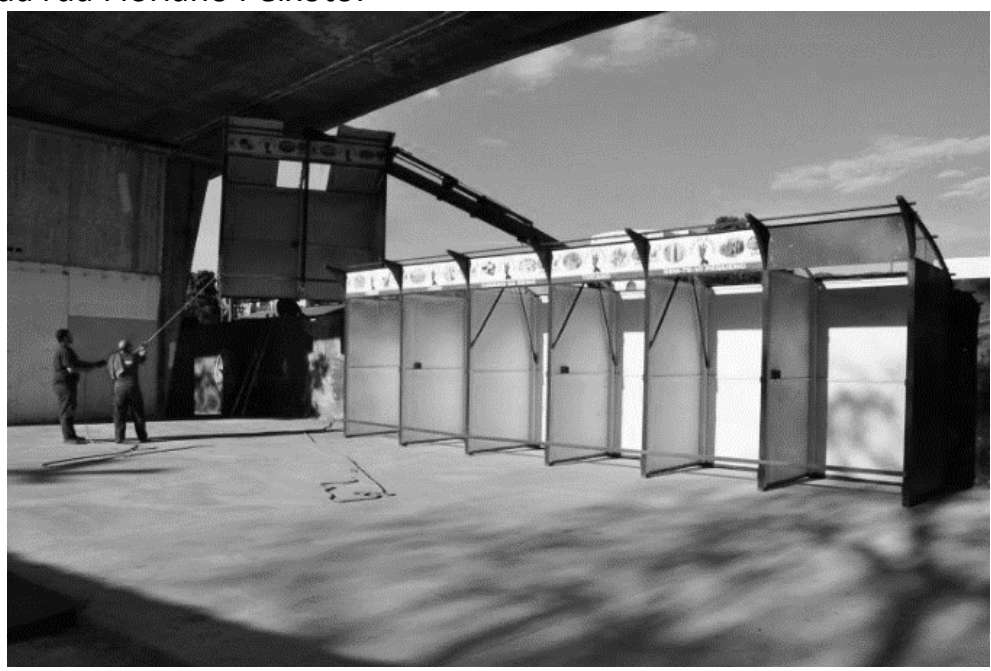

Fonte: Google Street View (2017). Editado pela autora, 2019.

Nesse caso, observa-se apenas uma preocupação com a regulamentação desses boxes excedentes não levando em consideração qualidade de vida do espaço, abrangendo uma gama de condicionantes como, clima, infraestrutura básica, mobilidade e conforto, como reforça Alvim (2019), Presidente Prudente resultam de um modelo de desenvolvimento urbano que, em geral, desconsidera a importância vital de seus espaços públicos como espaços da memória e local de diversidade sociocultural da cidade.

\section{CONSIDERAÇÕES FINAIS}

Nesse sentido entende-se que não houve uma comunicação entre os desejos para o futuro com o local de inserção, o viaduto foi implantado em um espaço que se já obtinha uma barreira física, a linha, agregado com o muro dela, além de vias que não contribuem para uma passagem tranquila. E a falsa ideia sobre a aparência do viaduto que não contribui, quando esses fatos estão mais ligados a falta de perspectiva do usuário.

Junto à isso nenhuma diretriz para o uso do baixio, nota-se que, o termo "não uso" fica incorreto a partir daqui, ele tem uso, deve-se refletir sobre os usos com vitalidade, diversidade e principalmente segurança, aquele que serve se transitório e proporciona qualidade de vida.

Nota-se que removendo os 32 boxes, ou não, a previsão é que a barreira visual permaneça, em ambas imagens é perceptível os fundos dos boxes em direção à linha, deixando então, parte dos problemas sem resolução.

\section{REFERÊNCIAS}

ABREU, D. S. Formação histórica de uma cidade pioneira paulista: Presidente Prudente. Presidente Prudente: FFCLPP, 1972

ALVIM, B. A. Memórias e atualidade - espaços públicos da área central de Presidente Prudente. 222.01 Presidente Prudente ano 19, jan. 2019 
AGOSTINI, F.; CAJADO, L.; TEIXEIRA, C. Projeto baixios de viadutos da via expressa leste-oeste. Arquitexto, 2005.

DEBORD, G. A sociedade do espetáculo. 1967. 2003. Disponível online em: https://www.marxists.org/portugues/debord/19 67/11/sociedade.pdf. Acesso em: 10 set. 2018.

GAVAZZA, N. A cidade de Jane Jacobs e o planejamento urbano. 137.02 ano 12 , maio 2013.

GROSTEIN, M. D. A leste do centro: territórios do urbanismo. São Paulo: Imprensa Oficial, 2010.

HIRAO, H. Paisagem histórica de Presidente Prudente (Vila Marcondes e Vila Goulart): cenário e atmosfera na cidade atual. In: COLÓQUIO IBERO-AMERICANO PAISAGEM CULTURAL, PATRIMÔNIO E PROJETO, 40. Anais ... 2008.

KOOLHAAS, R.; BOERI, S.; KWINTER, S.; TAZI, N. Mutaciones. Barcelona: Actar, 2000.

PEREIRA, L. A. G.; LESSA, S. N. O processo de planejamento e desenvolvimento do transporte rodoviário no Brasil. Caminhos de Geografia Revista On Line, 2011. Disponível online em: http://www.seer.ufu.br/index.php/caminhosdeg eografia/article/view/16414

FRANGELLA, S. M. Corpos urbanos errantes: uma etnografia da corporalidade de moradores de rua em São Paulo. São Paulo: Anablume, Fapesp, 2009. p. 361.

SÁNCHEZ, F. Políticas urbanas em renovação: uma leitura crítica dos modelos emergentes. Revista Brasileira de Estudos Urbanos e Regionais, n.1, mai-nov. 1999. https://doi.org/10.22296/2317-

$\underline{1529.1999 n 1 \mathrm{p} 115}$ 